\title{
Effects of Different Hydroponics Systems and Growing Media on Physiological Parameters of Spinach
}

\author{
Dinkar J. Gaikwad*, Srija Priyadarsini and Biswajit Mallick
}

Department of Plant Physiology, M.S. Swaminathan School of Agriculture, Centurion

University of Technology and Management, Paralakhemundi, Pin-761211, Odisha, India

*Corresponding author

\begin{tabular}{l} 
Ke y w o r d s \\
Hydroponics, NFT, \\
Growing media, \\
Spinach, Leaf area, \\
Yield \\
\hline Article Info \\
$\begin{array}{l}\text { Accepted: } \\
10 \text { April } 2020 \\
\text { Available Online: } \\
\text { 10 May } 2020\end{array}$
\end{tabular}

Keywords

Hydroponics, NFT, Growing media, Spinach, Leaf area, Yield

Accepted:

10 April 2020 10 May 2020

\section{A B S T R A C T}

The experiment was conducted during rainy season of the year 2018 at M.S. Swaminathan School of Agriculture, Centurion University of Technology and Management, Paralakhemundi, Odisha. This study attempted to investigate the potential of growing spinach using different hydroponics systems. For the cultivation of leafy vegetables, two different Hydroponic structures were designed like A-Frame hydroponics system and elevated trays hydroponics system. Three different types of growing media were used i.e. sawdust, coco peat and sterilized absorbent cotton. Modified Hoagland solution was used as a liquid medium. Data were collected on growth parameters like survival rate of seedlings, leaf length, leaf width, leaf area and fresh weight of foliage. The result showed that all physiological parameter values were recorded highest from plants grown in sawdust in the A frame hydroponics structure. Plants grown in coco peat media were at par to sawdust media in most of the cases while the lowest values were obtained in plants grown in sterilized absorbent cotton in the elevated tray hydroponics system.

\section{Introduction}

Hydroponics is a science of growing plants using a solution of suitable nutrients instead of soil and considered one of the most innovative agricultural strategies to produce more from less, in order to feed the estimated 11 billion people in the world by 2100 (Lal, 2016). This can either be through the use of non-soil growing medium or no growing medium at all. The plants thrive on the nutrient solution alone. The growing media, if any, is totally inert and merely acts as a support for the plants and their root systems, while the nutrient solution passes freely. Though, growing media plays an important role in seed germination, seedling growth and vigour in hydroponics. Several studies reported the favorable effect that organic materials have on plant growth (Hardgrave and Harriman, 1995; Ayuso et al., 1996; Tzortzakis and Economakis, 2005, 2008). 
Different environmental friendly substrates, alternative substrates derived from residues such as sawdust (Dorais et al., 2005), wood fiber (Muro et al., 2005; Jackson and Wright, 2009), coco coir (Noguera et al., 2000) has been already tested in the past.

Sawdust is affordable as compared to imported growing media, and it is suitable for use as a growing medium. Many Researchers have reported the favorable effect that organic growing media have on plant growth (Tzortzakis \& Economakis, 2008; Maboko et $a l ., 2013$ ), as it increased the porosity and water retention of the growing medium (Hardgrave \& Harrisman, 1995; Marinou et al., 2013). Positive physical properties such as biogradability at an acceptable rate, low superficial specific gravity, high porosity, high water retention, moderate drainage and high bacterial tolerance elevated the usage of sawdust as a plant growth medium in manufacturing industries (Maharani et al., 2010). Despite the fact that sawdust has been commercially used for many years, data is lacking that describes whether sawdust is suitable for vegetable production as a growth substrate.

Cocopeat is a byproduct separated during processing of coconut coir. As a byproduct of coir manufacturing, cocopeat is often unutilized or burnt in the open. Of late, due to environmental concerns and also diminishing supplies of peat soils for horticulture substrates, cocopeat is being considered as a renewable peat substitute for the use in horticulture (Yau and Murphy, 2000). Cocopeat has good physical properties, many pore space, high water content, low shrinkage, low bulk density and slow biodegradation. Basirat (2011) reported that Cocopeat can be used in germination of seeds, nursery raising, cutting rooting and other vegetative plant propagation methods, hydroponic systems of plant cultivation, cultivation of glass house plants, soil conditioning, etc. There are several different types of hydroponics system, but all share the same basic method of supplying the plants with nutrients and water. NFT was developed in the mid 1960s in England by Dr. Alen Cooper to overcome the shortcomings of ebb and flow system. In this system, water or a nutrient solution circulates throughout the entire system; and enters the growth tray via a water pump without a time control (Domingues et al., 2012). The system is slightly slanted so that nutrient solution runs through roots and down back into a reservoir. Plants are placed in channel or tube with roots dangling in a hydroponic solution. In deep water cultures, roots of plants are suspended in nutrient rich water and air is provided directly to the roots by an air stone. Elevated trays system is classical example of this system. Plants are placed in mesh pots and roots are suspended in nutrient solution where they grow quickly in a large mass.

In hydroponics system, many leafy green can easily be grown and commercially most widely used for lettuce production. Besides lettuce, recently various hydroponic experiments were conducted using spinach as model crop (Sharma et al., 2018). At the moment, utilization of hydroponics systems for the commercial production of crops is very limited. This study, therefore, attempted to investigate the potential of growing Spinach using different growing media in hydroponics systems.

\section{Materials and Methods}

The study was carried out in hydroponics unit belongs to M.S. Swaminathan School of Agriculture, Centurion University of Technology and Management, Paralakhemundi, Odisha during rainy season of 2018. Spinach seeds were placed in mesh pots having different growing media like sawdust, coco peat, and sterilized absorbent 
cotton. Pots were fixed on A-frame hydroponics system (NFT) and elevated trays system. Modified Hoagland solution is used as a source of nutrient solutions for both hydroponic systems. $\mathrm{pH}$ between 6.0 to 7.0 and $\mathrm{EC}\left(\mathrm{dSm}^{-1}\right)$ between 1.8 to 2.3 was maintained throughout the growing period of spinach (Sharma et al., 2018). Data were recorded on different growth parameters after 45 DAS from ten randomly selected seedlings of each treatment. This study was prepared in Factorial Experimental Design following the randomized block design (Randomized Completely Block Design). Consists of two factors, namely A Factor (Hydroponics systems) which consists of two levels; A1 = A frame hydroponics system and A2 = Elevated trays hydroponics system. B Factor (growing media) having three levels; namely: $\mathrm{B} 1=$ Saw dust, $\mathrm{B} 2=$ coco peat and B3 sterilized absorbent cotton. Factor B (Growing media) which is composed of three compositions combined with Factor A so that there were 6 combinations of treatments. Every combination of treatment was 5 replications, so there were 30 treatment units. The main parameters recorded in this study were the survival of seedlings $(\%)$, leaf length $(\mathrm{cm})$, leaf width $(\mathrm{cm})$, leaf area $\left(\mathrm{cm}^{2}\right)$ and yield (g/pot). Survival percentage was observed up to 10 days after sowing was calculated using the formulae as:

\section{Survival percentage $=$}

Total number of surviving seedling

Total number of transplanted seedling

\section{Results and Discussion}

The result of effect of different hydroponics system and non soil growing media on different parameters like survival percent, leaf length $(\mathrm{cm})$, leaf width $(\mathrm{cm})$ and leaf area $\left(\mathrm{cm}^{2}\right)$ is shown in Table 1 . The result shows that highest survival percentage of seedlings was observed in saw dust $(96.67 \%)$ followed by cocopeat $(94.00 \%)$ while lowest in sterilized absorbent cotton (84.67\%). Survival percentage in A-frame hydroponics system (93.33\%) significantly proved the best over elevated trays system $(90.22 \%)$. Hydroponics system $\mathrm{x}$ growing media interaction was found to be significant. Leaf length values also shows similar trend. Highest leaf length was observed in sawdust $(30.46 \mathrm{~cm})$ and lowest was in sterilized absorbent cotton $(22.86 \mathrm{~cm})$. Different hydroponics systems also have shown significance difference in the values of leaf length. Interaction between hydroponics systems and growing media was found to be non significant. Mean leaf width values were fluctuated between $9.47 \mathrm{~cm}$ in sawdust and $7.23 \mathrm{~cm}$ in sterilized absorbent cotton showing significant difference among growing medium. Leaf width values in hydroponics systems and interaction between factor A and Factor B was found to be non significant. Leaf area values were recorded significantly higher in sawdust $\left(182.51 \mathrm{~cm}^{2}\right)$ followed by cocopeat $\left(166.99 \mathrm{~cm}^{2}\right)$ and lowest in sterilized absorbent cotton (138.91 $\mathrm{cm}^{2}$ ). Leaf area values in A-frame hydroponics system $\left(166.82 \mathrm{~cm}^{2}\right)$ were significantly superior over elevated trays hydroponics system $\left(158.78 \mathrm{~cm}^{2}\right)$. Fresh foliage weight of spinach is shown in figure 1. Data revealed that fresh weight of foliage per mesh pot was significantly higher in sawdust, followed by cocopeat and lowest in sterilized absorbent cotton. However, Interaction between factor A and Factor B showed no significant difference in fresh weight values. Thus present study reveals that survival percentage, all morphological parameters and fresh foliage yield of spinach was observed highest in Sawdust media and at par in cocopeat in most of the cases and lowest in sterilized absorbent cotton. These results indicate that growing media like sawdust and cocopeat that used in this study can be 
categorized as a good growing media for hydroponics. These results are akin to the findings of Ramirez et al., (2014) in cherry tomato and Omokhua et al., (2015) in Terminalia ivorensis. Survival and growth are usually increased because of intensive contact between the roots with growing media and the nutrients and water holding capacity of the container media. Similar results were also obtained by Marjenah et al., (2016). Sterilized absorbent cotton isn't food source for plants or microbes showed least plant growth in both hydroponics systems.

Table.1 Effects of different hydroponics systems and growing media on the survival percent, leaf length, leaf width and leaf area of spinach

\begin{tabular}{lcccccccccccc}
\hline & \multicolumn{3}{c}{ Survival \% } & \multicolumn{3}{c}{ Leaf length $(\mathrm{cm})$} & \multicolumn{3}{c}{ Leaf width $(\mathrm{cm})$} & \multicolumn{3}{c}{ Leaf area $\left(\mathrm{cm}^{2}\right)$} \\
\hline Treatments & A1 & A2 & Mean B & A1 & A2 & Mean B & A1 & A2 & Mean B & A1 & A2 & Mean B \\
\hline B1 & 97.33 & 96.00 & 96.67 & 31.04 & 29.87 & 30.46 & 9.56 & 9.37 & 9.47 & 186.38 & 178.64 & 182.51 \\
B2 & 94.66 & 93.33 & 94.00 & 29.23 & 29.15 & 29.19 & 9.14 & 8.96 & 9.05 & 172.13 & 161.85 & 166.99 \\
B3 & 88.00 & 81.33 & 84.67 & 23.85 & 21.86 & 22.86 & 7.41 & 7.05 & 7.23 & 141.96 & 135.86 & 138.91 \\
\hline Mean A & 93.33 & 90.22 & 91.78 & 28.04 & 26.96 & 27.50 & 8.70 & 8.46 & 8.58 & 166.82 & 158.78 & 162.80 \\
\hline Factors & (A) & (B) & (A X B) & (A) & (B) & (A X B) & (A) & (B) & (A X B) & (A) & (B) & (A X B) \\
\hline CD & 1.690 & 2.070 & 2.928 & 0.819 & 1.003 & NS & NS & 0.503 & NS & 6.132 & 7.510 & NS \\
SE(d) & 0.805 & 0.985 & 1.394 & 0.390 & 0.477 & 0.675 & 0.195 & 0.239 & 0.338 & 2.919 & 3.575 & 5.056 \\
SE(m) & 0.569 & 0.697 & 0.985 & 0.276 & 0.338 & 0.477 & 0.138 & 0.169 & 0.239 & 2.064 & 2.528 & 3.575 \\
\hline
\end{tabular}

A1-A frame hydroponics system, A2- Elevated trays hydroponics system;

*** B1-Saw dust, B2-Cocopeat, B3-Sterilized absorbent cotton

Graph.1 Effect of different hydroponics systems and growing media on fresh foliage yield of spinach

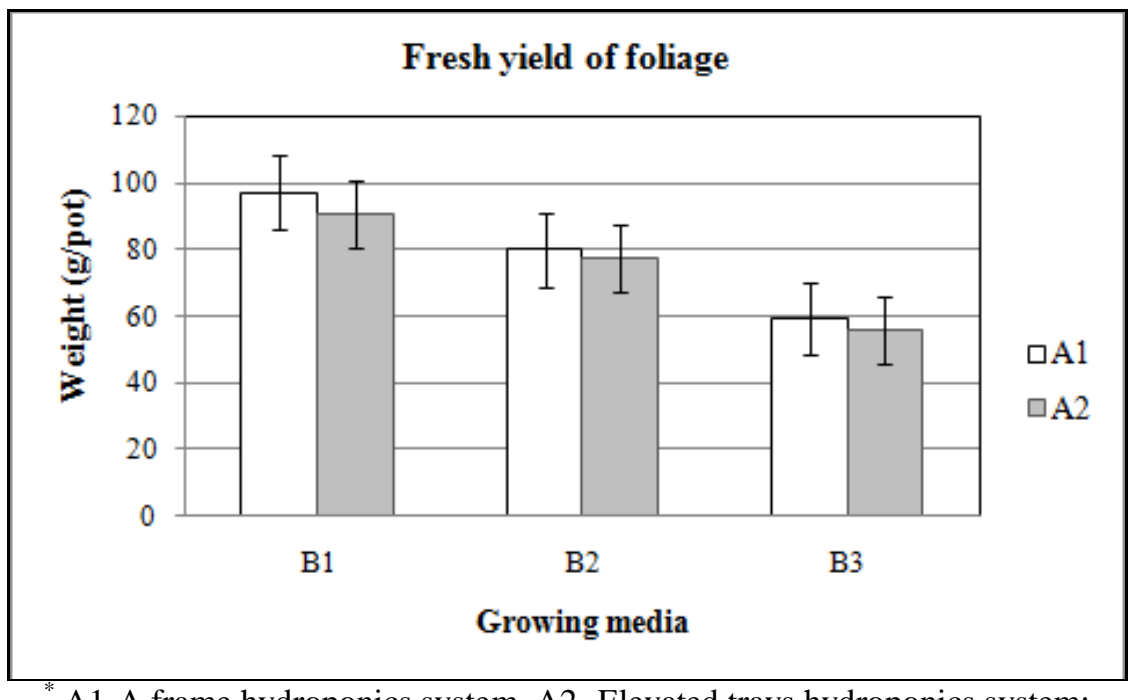

A1-A frame hydroponics system, A2- Elevated trays hydroponics system;

${ }^{* *}$ B1-Saw dust, B2-Cocopeat, B3-Sterilized absorbent cotton 
In conclusion, ccontinuous flow of nutrients solutions in A- Frame hydroponics system leads to exposure of adequate supplies of water, oxygen and nutrients to the roots of spinach when compared to elevated trays hydroponics system while sawdust and cocopeat should be used as growing medium in hydroponics as it is inducing the crop growth and yield of spinach.

\section{Acknowledgement}

The authors are thankful to M.S. Swaminathan School of Agriculture, Centurion University of Technology and Management for providing facilities to conduct this research work.

\section{References}

Ayuso, M., Hernandez, T. Garcia, C. and Pascual, J. A. 1996. Stimulation of barley growth and nutrient absorption by humic substances originating from various organic materials. Bioresourse Technology. 57: 251-257.

Basirat, M. 2011. Use of palm waste cellulose as a substitute for common growing media in Aglaonema growing. Journal of Ornamental and Horticultural Plants. 1(1): 1- 11.

Domingues, D.S., Takahashi, H.W., Camara, C.A.P. and Nixdorf, S.L. 2012. Automated system developed to control $\mathrm{pH}$ and concentration of nutrient solution evaluated in hydroponic lettuce production. Computers and Electronics in Agriculture. 84: 53-61.

Dorais, M., Caron, J., Bégin, G., Gosselin, A., Gaudreau, L. and Ménard, C. 2005. Equipment performance for determining water needs of tomato plants grown in sawdust based substrates and rockwool. Acta Horticulturae. 691:293-304

Hardgrave, M. and M. Harriman. 1995. Development of organic substrates for hydroponic cucumber production. Acta Horticulturae. 401: 219-224.

Jackson, B.E. and Wright, R.D. 2009. Pine tree substrate an alternative and renewable substrate for horticultural crop production. Acta Horticulturae. 819:265-272.

Lal, R. 2016. Feeding 11 billion on 0.5 billion hectare of area under cereal crops. Food and Energy Security, 5: 239-251.

Maboko, M. M. and DuPlooy, C.P. 2013. Highdensity planting of tomato cultivar's with early decapitation of growing point increased yield in a closed hydroponic system. Acta Agriculturae Scandinavica. 63: 676682.

Maharani, R., Tamai, Y., Takashi, Y. and Terazawa, M. 2010. Scrutiny of Physical Properties of Sawdust from Tropical Countries Wood Species: Effect of Different Mills and Sawdust Particle Size. Journal of Forestry Research. 7(1): 20-32.

Marinou, E. Chrysargyris, A. and Tzortzakis, N. 2013. Use of sawdust, coco soil and pumice in hydroponically grown strawberry. Plant Soil and Environment. 59(10): 452-459.

Marjenah, Kiswanto, Purwanti, S., Sofyan, F. P. M. 2016. The effect of biochar, cocopeat and saw dust compost on the growth of two dipterocarps seedlings. Nusantara Bioscience. 8(1): 39-44.

Muro, J., Irigoyen, I., Samitier, P., Mazuela, P., Salas, M.C., Soler, J. and Urrestarazu, M. 2005. Wood fiber as growing media in hydroponic crop. Acta Horticulturae. 697:179-185.

Noguera, P., Abad, M., Noguera, V., Puchades, R. and Maquiera, A. 2000. Coconut coir waste, anew and viable ecologically friendly peat substitute. Acta Horticulturae. 517:279-286.

Omokhua, G. E., Ogu, A. and Oyebade, B. A. 2015. Effects of different sowing media 
on germination and early seedling growth of Terminalia ivorensis (A.Chev.) International Journal of Scientific \& Technology Research. 4(3): 119-122.

Ramírez-Arias, A., Pineda-Pineda, J., Gutiérrez, M. and Ojeda-Bustamante, W. 2014. Sawdust and coco coir as growing media for greenhouse cherry tomatoes. Acta Horticulturae. 1037:1063-

1066. doi:10.17660/actahortic.2014.103 7.140 .

Sharma, N., Acharya S., Kumar K., Singh, N. and Chaurasia O.P. 2018. Hydroponics as an advanced technique for vegetable production: An overview. Journal of Soil and Water Conservation. 17(4):364-371.

Tzortzakis, N. G. and C. D. Economakis. 2005. Shredded maize stems as an alternative substrate medium. Effect on growth, flowering and yield of tomato in soilless culture. Journal of Vegetable Science. 11: 57-70.

Tzortzakis, N. G. and Economakis, C. D. 2008. Impacts of the substrate medium on tomato yield and fruit quality in soilless cultivation. Journal of Horticultural Science. 35(2): 83-89.

Wahome, P. K., Oseni, T. O., Masarirambi, M. T. and Shongwe, V. D. 2011. Effects of different hydroponics systems and growing media on the vegetative growth, yield and cut flower quality of Gypsophila (Gypsophila paniculata L.). World Journal of Agricultural Sciences. 7(6):692-698.

Yau, P. Y. and Murphy, R. J. 2000. Biodegraded cocopeat as a horticultural substrate. Acta Horticulturae. $\quad$ 517: 275-278. doi:10.17660/actahortic.2000.517.33.

\section{How to cite this article:}

Dinkar J. Gaikwad, Srija Priyadarsini and Biswajit Mallick. 2020. Effects of Different Hydroponics Systems and Growing Media on Physiological Parameters of Spinach. Int.J.Curr.Microbiol.App.Sci. 9(05): 1409-1414. doi: https://doi.org/10.20546/ijcmas.2020.905.160 